\title{
Modulation of Corneal Fibroblast Contractility within Fibrillar Collagen Matrices
}

\author{
Mridula Vishwanath, ${ }^{1}$ Lisha Ma, ${ }^{1}$ Carol A. Otey, ${ }^{2}$ James V. Jester, ${ }^{1}$ and \\ W. Matthew Petroll
}

PurPose. To investigate the migratory and contractile behavior of isolated human corneal fibroblasts in fibrillar collagen matrices.

Methods. A telomerase-infected, extended-lifespan human corneal fibroblast cell line (HTK) was transfected by using a vector for enhanced green fluorescent protein (GFP)- $\alpha$-actinin. Cells were plated at low density on top of or within $100-\mu \mathrm{m}$-thick fibrillar collagen lattices. After 18 hours to 7 days, time-lapse imaging was performed. At each 1- to 3-minute interval, GFP and Nomarski differential interference contrast (DIC) images were acquired in rapid succession. Serum-containing $(\mathrm{S}+) \mathrm{me}-$ dium was used initially for perfusion. After 2 hours, perfusion was switched to either serum-free $(\mathrm{S}-)$ or $\mathrm{S}+$ medium containing the Rho-kinase inhibitor Y-27632 for 1 to 2 hours. Finally, perfusion was changed back to $S+$ medium for 1 hour.

Results. Two to 4 days after plating, many cells underwent spontaneous contraction and/or relaxation in $\mathrm{S}+$ medium. A decrease in the distance between consecutive $\alpha$-actinin-dense bodies along stress fibers was measured during contraction, and focal adhesion and matrix displacements correlated significantly. Removal of serum or inhibition of Rho-kinase induced cell body elongation and relaxation of matrix stress, as confirmed using finite element modeling. Rapid formation and extension of pseudopodia and filopodia were also observed, and transient tractional forces were generated by these extending processes.

Conclusions. Cultured human corneal fibroblasts can undergo rapid changes in the subcellular pattern of force generation that are mediated, in part, by Rho-kinase. Sarcomeric shortening of stress fibers in contracting corneal fibroblasts is also demonstrated for the first time. (Invest Ophthalmol Vis Sci. 2003;44:4724-4735) DOI:10.1167/iovs.03-0513

$\mathrm{C}$ ell-matrix mechanical interactions play a defining role in a gamut of biological processes, such as developmental morphogenesis and wound healing. During embryonic development, physical forces exerted by mesenchymal cells organize extracellular matrix (ECM) into a wide variety of spatial patterns whose mechanical properties lend structural support and give form and organization to vertebrate tissue. ${ }^{1-4}$ Similarly,

From the ${ }^{1}$ Department of Ophthalmology, Southwestern Medical Center, Dallas, Texas; and the ${ }^{2}$ Department of Cell and Molecular Physiology, University of North Carolina, Chapel Hill, North Carolina.

Supported by National Eye Institute Grant R01 EY13322 and an unrestricted grant from Research to Prevent Blindness, Inc.

Submitted for publication May 22, 2003; revised July 25, 2003; accepted August 3, 2003.

Disclosure: M. Vishwanath, None; L. Ma, None; C.A. Otey, None; J.V. Jester, None; W.M. Petroll, None

The publication costs of this article were defrayed in part by page charge payment. This article must therefore be marked "advertisement" in accordance with 18 U.S.C. $\$ 1734$ solely to indicate this fact.

Corresponding author: W. Matthew Petroll, Department of Ophthalmology, Southwestern Medical Center, 5323 Harry Hines Boulevard, Dallas, TX 75390-9057; matthew.petroll@utsouthwestern.edu. wound contraction and remodeling of connective tissue matrix are the result of mechanical interactions between fibroblasts and collagen fibrils. ${ }^{5-7}$ In the cornea, the process of wound repair after lacerating injury, penetrating keratoplasty, or photorefractive keratectomy (PRK) begins with the migration of epithelial cells from the edge of the wound to reestablish an intact surface. This is followed by the proliferation and migration of activated keratocytes (corneal fibroblasts) into the wound from the surrounding stroma and synthesis of new ECM. Finally, the apposition of the wound edges (wound contraction) and ECM reorganization (remodeling) are mediated by the application of mechanical force by fibroblasts on the collagen fibrils. Clearly, there is a strong motivation for understanding the interplay between the complex cellular, biochemical, and biomechanical phenomena controlling cell migration, contraction, and matrix remodeling during wound healing and tissue morphogenesis. An understanding of this process is also critical in the field of tissue engineering, in which it is necessary either to modulate ECM remodeling to produce a desired matrix architecture or to prevent matrix remodeling to preserve a prefabricated three-dimensional (3-D) structure. $^{8}$

Many insights into the mechanisms regulating cell-mediated matrix reorganization and wound contraction have been obtained by using the fibroblast-populated collagen lattice model. ${ }^{1,9-11}$ In this in vitro model, cells are plated inside 3-D fibrillar collagen matrices, and measurements of matrix contraction are used as an indicator of cellular mechanical activity and matrix remodeling. Alternatively, force transducers can be used to measure the overall isometric tension generated by the fibroblasts inside the matrix. ${ }^{12-14}$ Although these global measurements have provided valuable insights into the signaling pathways involved in various aspects of cell-matrix mechanical interactions, ${ }^{15-22}$ an understanding of how force generation and matrix reorganization is regulated at the subcellular level can only be obtained by studying these processes dynamically in individual cells. Many such studies have been performed in which planar elastic substrates were used, such as silicone or collagen-coated polyacrylamide sheets. ${ }^{23-31}$ However, these models do not allow assessment of cell-induced collagen matrix reorganization and remodeling, a critical component of wound healing. Furthermore, cells reside within 3-D extracellular matrices in vivo, and ECM geometry has been shown to affect cell morphology and adhesion organization and composition. . 32-36 $^{3,3}$

We recently developed and applied a new experimental model for directly investigating cell-matrix mechanical interactions by plating GFP-zyxin-transfected cells at very low density, either inside or on top of fibrillar collagen matrices and performing high-magnification time-lapse differential contrast (DIC) and fluorescence imaging. ${ }^{37,38}$ With this approach, focal adhesion movement and reorganization in isolated rabbit corneal fibroblasts was directly correlated with collagen matrix deformation 18 to 24 hours after plating. The data suggest that cell migration requires generation of both rearward-directed tractional force at the leading edge (spreading) and musclelike contractile force along the cell body (contraction). In this 
study, we investigated whether spreading and contraction are differentially regulated by examining human corneal fibroblasts transfected to express GFP- $\alpha$-actinin, 18 hours to 7 days after plating. Because contraction of collagen matrices by fibroblasts is largely dependent on the presence of serum or added growth factors in the medium, ${ }^{39-42}$ we first studied the effects of serum removal on subcellular mechanical activity. Removal of serum induced a rapid and reversible relaxation of contractile forces along the cell body. Unexpectedly, active extension of pseudopodia was also observed, with maintenance of tractional force. Previous studies in other cell types have shown that the small guanosine triphosphatases (GTPases) Rho and Rac regulate cellular contraction and spreading, respectively. ${ }^{43}$ Thus, we next investigated whether corneal fibroblast contraction could be more specifically inhibited by blocking Rhokinase, a downstream effector of Rho. Addition of the Rhokinase inhibitor Y-27632 induced a similar but more rapid and dramatic inhibition of cell contraction and stimulation of cell spreading than did serum removal. Overall, these results are consistent with previous studies in other cell types, suggesting that the balance between Rho and Rac activity determines both the rate of cell spreading and migration ${ }^{43,44}$ and the amount of cell-induced matrix contraction and remodeling, ${ }^{18,45}$ two fundamental components of wound healing and developmental morphogenesis. We also demonstrate for the first time that there is sarcomeric shortening of stress fibers in contracting fibroblasts, supporting a role for stress fibers in cellular force generation during corneal wound contraction.

\section{Materials ANd Methods}

\section{Cells}

All studies were performed with a previously characterized telomeraseinfected, extended-lifespan human corneal fibroblast cell line, HTK. ${ }^{46}$ HTK cells were cultured in complete (serum-containing, $\mathrm{S}+$ ) medium consisting of modified Eagle's minimum essential medium (MEM; Sigma-Aldrich, St. Louis, MO), supplemented with $1 \%$ penicillin, $1 \%$ streptomycin, and 1\% amphotericin B (Fungizone; BioWhittaker, Inc., Walkersville, MD) and 10\% fetal bovine serum (FBS; Sigma-Aldrich).

\section{Transfection}

For expression of GFP- $\alpha$-actinin, human $\alpha$-actinin in a pEGFP-N1 vector (BD Biosciences-Clontech Laboratories, Inc., Palo Alto, CA) was used. This probe has successfully been used to visualize $\alpha$-actinin in Swiss 3T3 cells. $^{47-49}$ Corneal fibroblasts were plated on six-well plates (40,000 cells/well) using complete medium without antibiotics 24 hours before transfection. Transfection was performed with a commercial reagent (LipofectaminePLUS; Invitrogen, Carlsbad, CA), as described previously. ${ }^{37}$ The EGFP vector has a neo selection cassette, and thus transfected HTK cells were selected using complete medium containing G418. GFP- $\alpha$-actinin- expressing cells were further selected using fluorescence-activated cell sorting. Untransfected HTK cells were used as the control.

\section{Immunocytochemistry and Western Blot Analysis}

To confirm that GFP- $\alpha$-actinin was being organized into focal adhesions and stress fibers, HTK cells were cultured for 18 hours and counterstained for vinculin and F-actin, as described previously. ${ }^{37}$ To determine the relative expression levels of native $\alpha$-actinin and GFP- $\alpha$ actinin, Western blot analysis was performed on both control and GFP- $\alpha$-actinin transfected cells. Proteins were run on $7.5 \%$ SDS polyacrylamide gels and transferred to nitrocellulose. Nonspecific binding was blocked with $5 \%$ milk, and membranes were incubated with a mouse anti-human $\alpha$-actinin antibody diluted 1:1000 (Sigma-Aldrich). Membranes were then washed and incubated in horseradish peroxidase-conjugated goat anti-mouse IgG (1:1000; Jackson ImmunoRe-
Table 1. Number of Time-Lapse Experiments Performed at Each Time Point

\begin{tabular}{lcccc}
\hline \multicolumn{1}{c}{ Media } & 18-24 h* & 2 days* & 3 days* & 5-7 days* \\
\hline $\mathrm{S}+$ & 4 & 4 & 4 & 3 \\
$\mathrm{~S}+\rightarrow \mathrm{S}-$ & 2 & 3 & 3 & - \\
$\mathrm{S}+\rightarrow \mathrm{S}++\mathrm{Y}-27632$ & 2 & 2 & 2 & - \\
\hline
\end{tabular}

* Incubation time before time-lapse imaging.

search, West Grove, PA) for 1 hour. Proteins were detected using by chemiluminescence (Enhanced ChemiLuminescence; Amersham Biosciences, Piscataway, NJ), and quantified using digital imaging (1-D Gel Scan Analysis Module; MetaMorph software; Universal Imaging Corp., Downingtown, PA).

\section{Collagen Matrices}

Hydrated collagen matrices were prepared as described previously. ${ }^{37,38}$ Briefly, neutralized bovine dermal collagen (Vitrogen 100; Collagen Corp., Palo Alto, CA) was mixed with $10 \times$ MEM to achieve a final collagen concentration of $2.48 \mathrm{mg} / \mathrm{mL}$. For plating inside the matrix, a 50- $\mu \mathrm{L}$ suspension of GFP- $\alpha$-actinin transfected or HTK control cells was mixed with $500 \mu \mathrm{L}$ of collagen solution. The cell-collagen mixture was preincubated at $37^{\circ} \mathrm{C}$ for 5 minutes, and $30-\mu \mathrm{L}$ aliquots (containing approximately 1000 cells) were then poured onto culture dishes (Delta T; Bioptechs, Inc., Butler, PA), placed in a humidified incubator $\left(37^{\circ} \mathrm{C}, 5 \% \mathrm{CO}_{2}\right)$ for 60 minutes for polymerization, and overlaid with $2 \mathrm{~mL}$ of complete medium. For plating of cells on top of the collagen matrix, the collagen solution (without cells) was first incubated for 60 minutes for polymerization, and $100 \mu \mathrm{L}$ of cell suspension (containing approximately 500 cells) was then seeded on top of the matrix. After incubation for 30 minutes to promote cell attachment, matrices were overlaid with $2 \mathrm{~mL}$ of complete medium.

\section{Time-Lapse Digital Imaging}

Collagen matrices were incubated for 18 hours to 7 days before each time-lapse imaging experiment. Microscopy was performed with an inverted microscope equipped for time-lapse fluorescence and DIC imaging (model TE300; Nikon Inc., Melville, NY). ${ }^{37,38}$ The hardware was controlled using a computer running image-analysis software (MetaMorph; Universal Imaging Corp.). To maintain cell viability during imaging, a microincubation system and objective heater were used (Bioptechs). While on the microscope stage, cells were continuously perfused with complete medium containing $50 \mathrm{mM}$ HEPES buffer at a rate of $6 \mathrm{~mL} / \mathrm{hour}$.

Cells were allowed to acclimate to the microscope's microincubation system for 1 hour before time-lapse imaging. The activity of a single cell was then imaged for up to 5 hours using a $60 \times$ oilimmersion objective (1.3 numeric aperture [NA], 220- $\mu \mathrm{m}$ free working distance). At each time point, separate FITC (for EGFP) and DIC images were acquired in rapid succession, as described previously. ${ }^{37}$ In most experiments, 3-D data sets were obtained at each time point by repeating the acquisition at five to six sequential focal planes in $z$ steps of 2 to $3 \mu \mathrm{m}$. To minimize phototoxicity and photobleaching, neutraldensity filters were used, and exposure times were kept to a minimum by using $2 \times 2$ on-chip camera binning.

\section{Modulation of Cell Contractility}

To modulate cell contractility, three sets of experiments were performed (Table 1). In the first set of experiments (15 cells), time-lapse imaging (1-3-minute intervals) was performed for up to 4 hours while cells were perfused with complete medium. In the second set of experiments (eight cells), after 1 to 2 hours of perfusion with complete medium, the perfusion was switched to serum-free $(\mathrm{S}-$ ) medium consisting of DMEM supplemented with 1\% RPMI 1640 vitamin and glutathione mix, $1 \%$ ascorbic acid, and 1\% MEM nonessential amino 

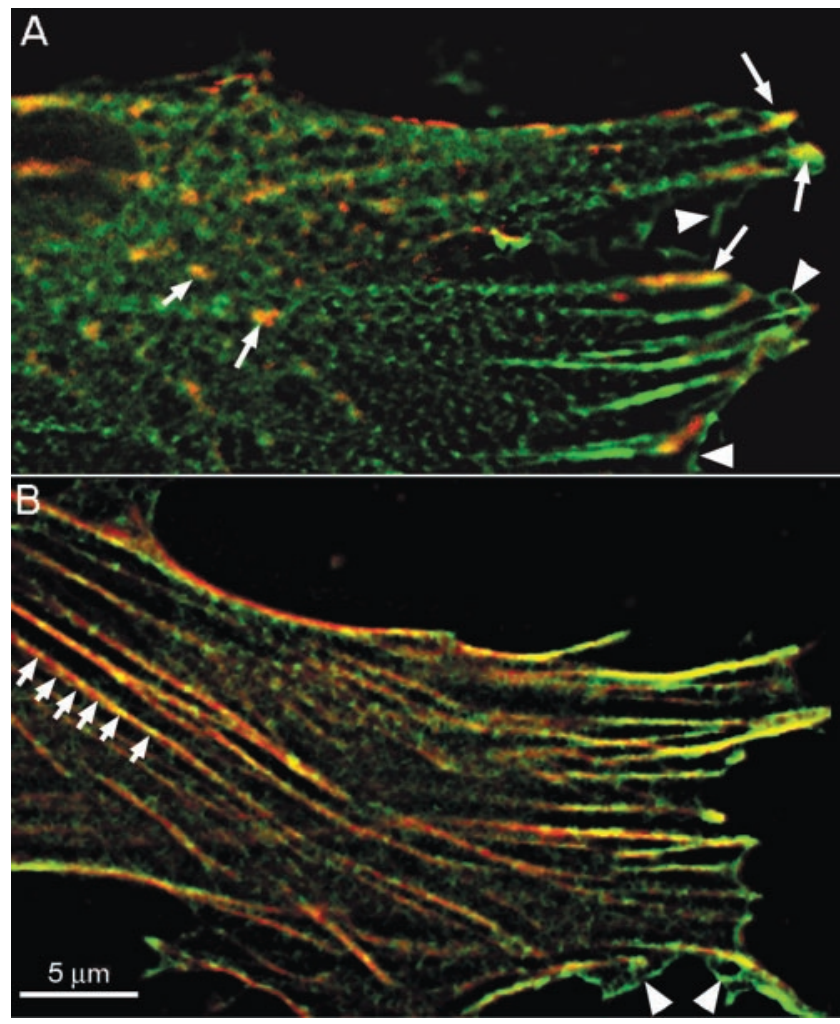

FIGURE 1. (A) Vinculin (red) counterstaining of GFP- $\alpha$-actinin (green)transfected HTK cells plated on glass. GFP- $\alpha$-actinin was incorporated into focal contacts, as indicated by yellow areas of colocalization (arrows). (B) Rhodamine phalloidin (red) counterstaining of GFP- $\alpha$ actinin (green)-transfected HTK cells plated on glass. GFP- $\alpha$-actinin was organized in a punctate, periodic pattern along stress fibers (arrows). GFP- $\alpha$-actinin was also localized to the leading edge of lamellipodia where membrane ruffling occurred (A, B, arrowheads).

acids. After 60 minutes, perfusion was changed back to complete medium for 1 to 2 hours to assess reversibility. In the third set of experiments (six cells), after 1 to 2 hours of perfusion with complete medium, $4 \mu \mathrm{L}$ of a $5 \mathrm{mM}$ stock solution of the Rho-kinase inhibitor Y-27632 (CalBiochem, La Jolla, CA) was added to the culture dish (Bioptechs) to achieve a final concentration of $10 \mu \mathrm{M}$. The perfusion medium was simultaneously switched to complete medium containing $10 \mu \mathrm{M}$ Y-27632. After 60 minutes, perfusion was changed back to complete medium for 1 to 2 hours to assess reversibility. At the end of every experiment, cytochalasin D (Sigma-Aldrich) was added to the culture dish (final concentration of $25 \mu \mathrm{M}$ ). Cells were then lysed using $1 \%$ Triton X-100 (Sigma-Aldrich). It should be noted that before starting time-lapse imaging of a single cell in each experiment, the morphology and GFP- $\alpha$-actinin organization of several additional cells in the collagen matrix were assessed.

\section{Image Processing and Analysis}

Image processing, 3-D reconstructions, and color overlays were performed on computer (MetaMorph; Universal Imaging Corp.). To map the ECM deformation, the movement of landmarks in DIC images was measured using the "track points" and "track objects" features in the software, as described previously. ${ }^{37,38}$ To measure the location and morphometry of focal adhesions over time, we used the integrated morphometry analysis (IMA) feature in the software, as described previously. ${ }^{37}$ The change in distance between consecutive GFP- $\alpha$ actinin-dense bodies along stress fibers was also measured using track points in three cells.

\section{Finite Element Modeling}

To quantify the cell-induced elastic distortion of the collagen matrix, strain maps were generated using finite element modeling (FEM), as described previously. ${ }^{50}$ Briefly, a FEM was created with engineering analysis software (ANSYS, ver. 7.0; ANSYS, Inc., Canonsburg, PA) by defining nodes at $x, y$ coordinates coinciding with ECM landmarks from the DIC images at the "relaxed" matrix configuration, which was determined by treating cells with cytochalasin D and Triton X-100. An extra set of fixed-boundary nodes was also placed in a $600-\mu \mathrm{m}$ circle around the cell. A two-dimensional finite element model was created from the nodes, using linear triangular elements (PLANE2 in the ANSYS software). The matrix was assumed to be linearly elastic and isotropic, with a Young's modulus of $3.89 \times 10^{-10} \mathrm{~N} / \mu \mathrm{m}^{2}$ and an effective thickness of $15 \mu \mathrm{m}$. These parameters were determined by simulating our previous force-displacement measurements on collagen matrices (made using calibrated microneedles) in a 3-D finite element model, ${ }^{51}$ and further confirmed by measuring the indentation induced by placing disks of known weight on top of the matrix. ${ }^{52,53}$ A Poisson's ratio of 0.3 was used. ${ }^{54}$ To generate a map of ECM deformation, the displacements (relative to the relaxed matrix configuration) measured in time-lapse recordings were applied to the corresponding nodes in the model, and the resultant strains induced on the matrix were calculated and displayed.

\section{Results}

\section{Immunocytochemistry and Western Blot Analysis}

Vinculin counterstaining of transfected HTK cells plated on coverslips demonstrated that GFP- $\alpha$-actinin was incorporated into focal contacts (Fig. 1A, arrows). In addition, GFP- $\alpha$-actinin was organized in a punctate, periodic pattern of dense bodies along stress fibers, as confirmed using F-actin counterstaining (Fig. 1B, arrows). GFP- $\alpha$-actinin was also localized to the ruffling edge of lamellipodia (Figs. 1A, 1B, arrowheads). Overall, the organization of GFP- $\alpha$-actinin was consistent with the previously established organization of endogenous $\alpha$-actinin. ${ }^{55-57}$ Because overexpression of cytoskeletal proteins can alter cell behavior, we used Western blot analysis to determine the level of GFP- $\alpha$-actinin expression. As shown in Figure 2, both control and transfected cells had a large band with an approximate molecular weight of $96 \mathrm{kDa}$, consistent with the expected mass of $\alpha$-actinin (100 kDa). Transfected cells had an additional band with an approximate molecular weight of $126 \mathrm{kDa}$, consistent with the expected mass of the two fused proteins (100

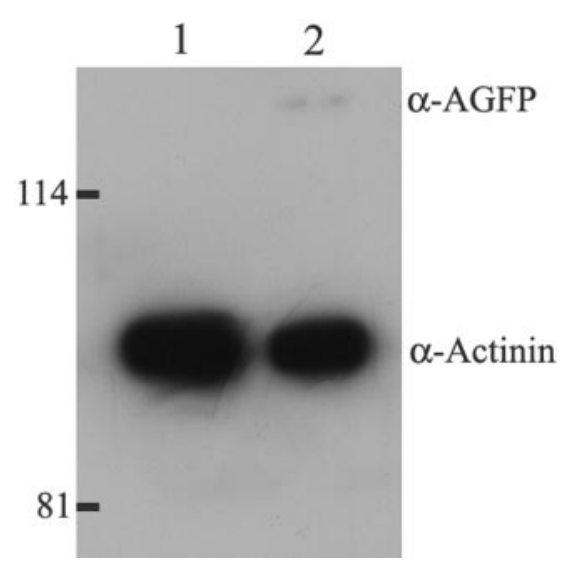

Figure 2. Western blot showing relative levels of endogenous and transfected $\alpha$-actinin. Equal amounts of cell lysate from control (lane 1) and transfected (lane 2) HTK cells were quantified with an anti- $\alpha$ actinin antibody. In transfected cells, only $1.5 \%$ of all $\alpha$-actinin within the cells was fused to GFP ( $\alpha$-AGFP). 
Figure 3. Processing of GFP and DIC images. (A) DIC image showing human corneal fibroblast inside fibrillar collagen ECM 18 hours after plating. (B, C) Two 2-D GFP- $\alpha$-actinin images from a seven-image stack are shown $(z$ indicates distance from bottom of matrix). Labeling of a stress fiber (B, large arrow) and focal adhesions (B, $\mathbf{C}$, small arrows) is observed. (D) Color overlay of GFP$\alpha$-actinin 3-D reconstruction (green) and 2-D DIC image (red) allows interactions between focal adhesions and collagen fibrils to be directly visualized. (E-F) Two images from the time-lapse sequence are shown. Matrix displacements are indicated in (F) by red tracks $(+$, starting positions at $t=10$ minutes). The collagen fibrils in front are pulled inward as the cell body and surrounding ECM moves forward, resulting in localized ECM compression (F, arrows). See Video 1 (refer to Appendix).

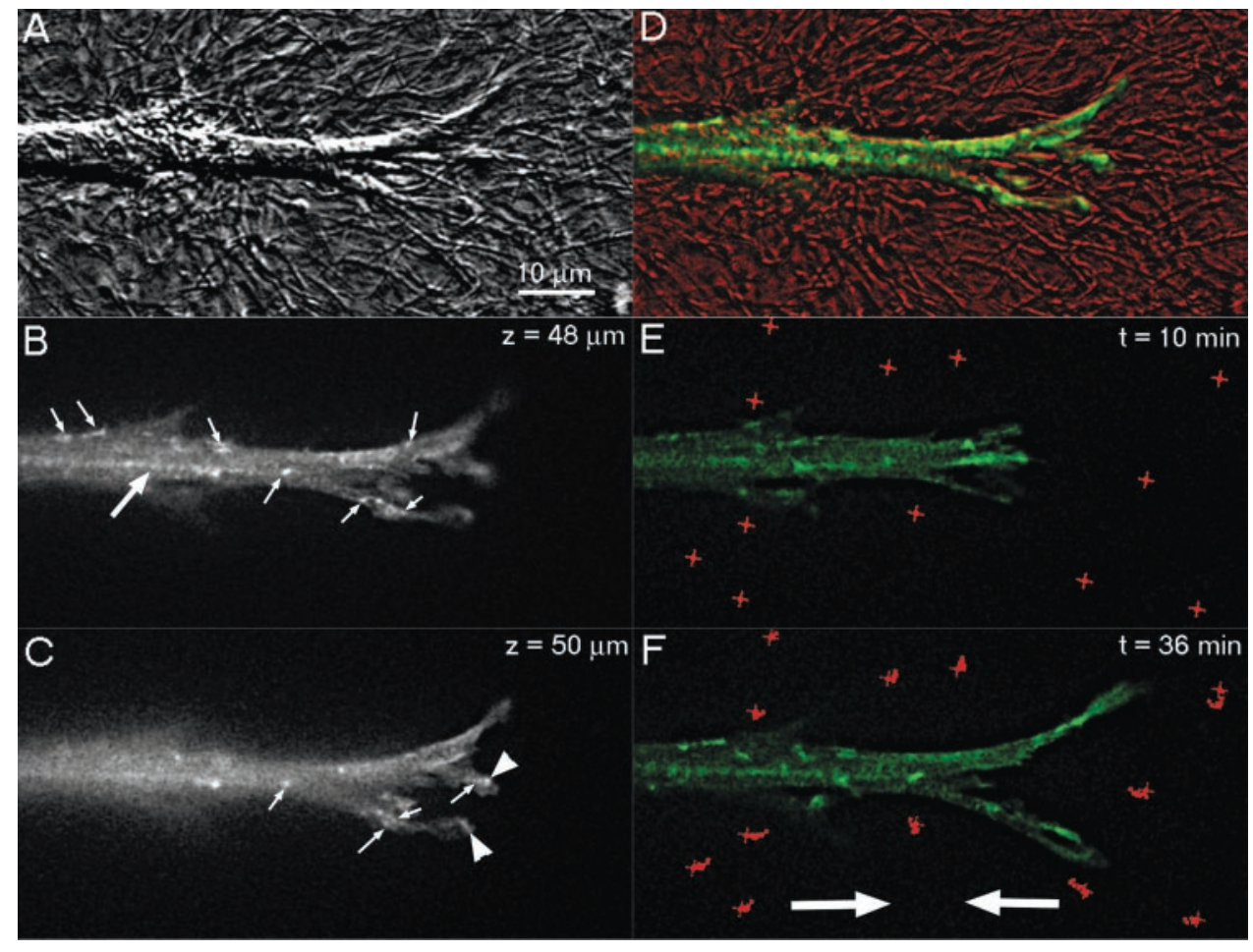

FIGURE 4. Spontaneous contraction and relaxation of corneal fibroblasts in $\mathrm{S}+$ medium. (A-C) Cell 2, 3 days after plating within collagen matrix. During perfusion with $\mathrm{S}+$, the entire cell began to contract and generate tension on the ECM as visualized by matrix displacements (B, C red tracks, +, starting positions). A corresponding movement of focal adhesions (A, B small arrows) was observed (compare white and red tracks in C). Stress fibers (A, B, large arrows) were also aligned with the ECM displacements. See Video 2 (refer to Appendix). (D-F) Cell 3,2 days after plating on top of collagen matrix. Cell began to relax spontaneously during perfusion with $\mathrm{S}+$ medium. Cell elongation correlated with release of tension on the ECM as demonstrated by the matrix displacements (red tracks). A corresponding movement of focal adhesions (D, E small arrows) was observed (compare white and red tracks in F). Stress fibers (D, E arrows) were also aligned with the measured ECM displacements. See Video 3 (refer to Appendix).

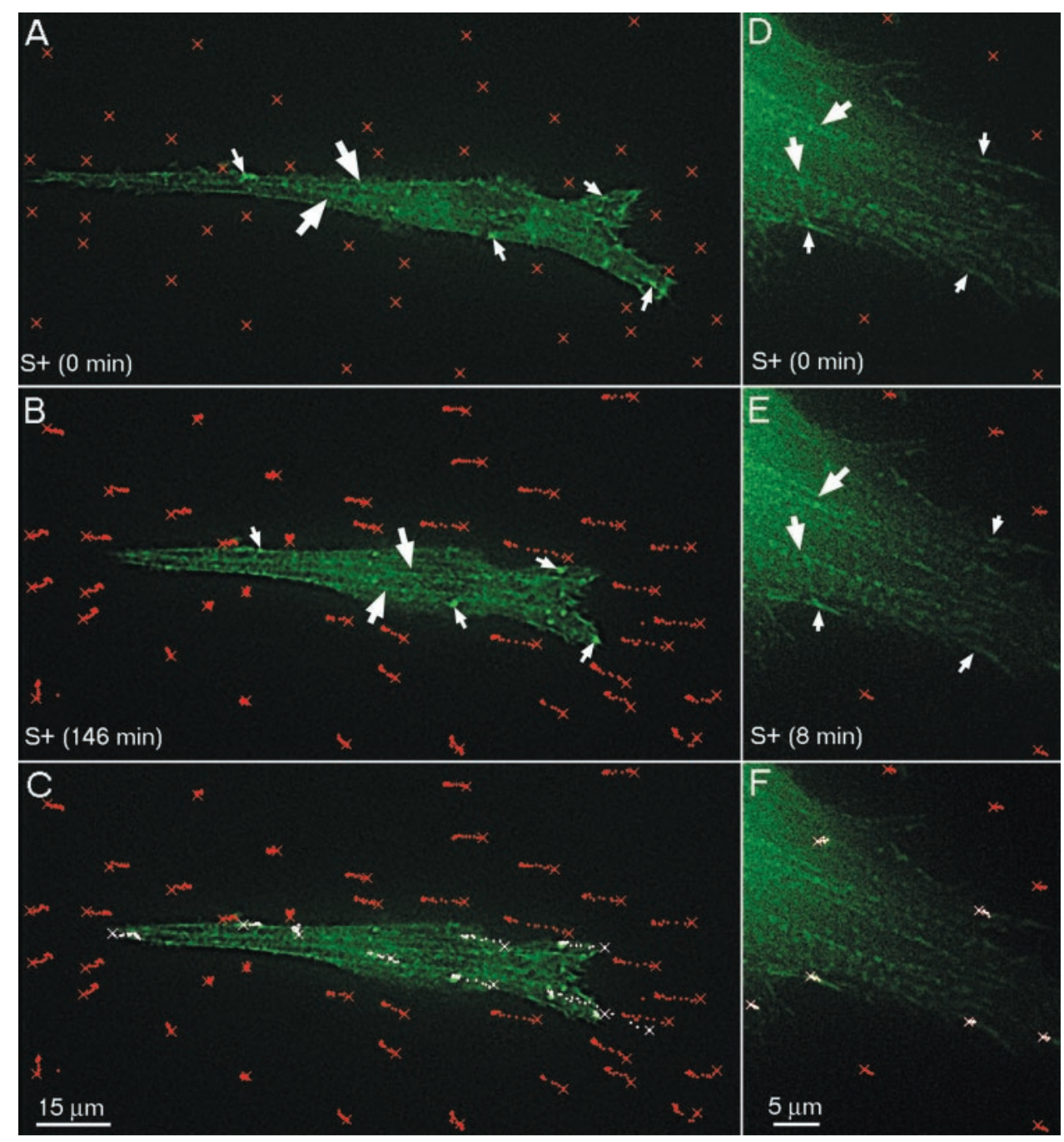

Downloaded from iovs.arvojournals.org on $09 / 15 / 2021$ 
$\mathrm{kDa}$ for $\alpha$-actinin and $27 \mathrm{kDa}$ for GFP). Quantitative analysis revealed that only $1.5 \%$ of all $\alpha$-actinin in the transfected cells was fused to GFP. This is consistent with previous studies demonstrating approximately $1 \%$ expression in mouse Swiss 3 T3 cells using the same GFP- $\alpha$-actinin construct. ${ }^{47}$ Transfected HTK cells had a morphology and mechanical activity similar to that of the untransfected control cells, further demonstrating that expression of GFP- $\alpha$-actinin did not alter cell behavior.

\section{Cell Mechanical Behavior 18 Hours after Plating}

HTK cells plated inside 3-D collagen matrices generally had a bipolar morphology with thin pseudopodial processes, whereas cells on top formed broader lamellipodial processes, consistent with previous observations in rabbit corneal fibroblasts. ${ }^{37,38,50}$ Cells were always aligned nearly parallel to the dish on which the collagen matrix was plated. DIC imaging allowed detailed visualization of the cells and the individual collagen fibrils surrounding them (Fig. 3A). In general, collagen fibrils inside the matrices were more clearly visualized than those on top of the matrix.

GFP- $\alpha$-actinin was organized into adhesions along both the pseudopodia and the cell body (Figs. 3B, 3C, small arrows). Unlike cells on rigid substrates (not shown), well developed stress fibers with bright GFP- $\alpha$-actinin labeling were not observed 18 to 24 hours after plating inside or on top of collagen matrices. However, some cells did have one or two detectable stress fibers with weaker GFP- $\alpha$-actinin labeling in a periodic pattern (Fig. 3B, large arrow). Diffuse background GFP- $\alpha$-actinin labeling was also present, suggesting a cytoplasmic pool of this protein. Because all the GFP- $\alpha$-actinin labeling was not visible in a single plane (compare Figs. 3B and 3C), 3-D reconstructions of the $z$-series were generated. Overlaying of GFP$\alpha$-actinin maximum intensity projections and individual DIC images allowed the organization of focal adhesions and collagen fibrils to be compared directly (Fig. 3D).

Eighteen hours after plating, human corneal fibroblasts, both on top of and within fibrillar collagen matrices, repeatedly extended and retracted pseudopodia during cell migration. In most cells, pseudopodial extension occurred at the front of the cells, whereas the rear was much less active and underwent intermittent retractions. The tips of extending pseudopodia were labeled by GFP- $\alpha$-actinin (Fig. 3C, arrowheads). The dynamic interactions between focal adhesions and collagen fibrils are best appreciated in time-lapse color overlay movies. Using high-magnification DIC imaging, movement and realignment of collagen fibrils during cell migration could be directly observed (Fig. 3; see Video 1 in Appendix).

Tracking of the ECM displacements allowed the pattern of matrix deformation during cell migration to be quantified (Figs. $3 \mathrm{E}, 3 \mathrm{~F}$, red tracks). Extension of pseudopodial processes generated tractional forces on the ECM, as indicated by pulling in of the ECM in front of the cell (Figs. 3E, 3F). At the same time, the cell body and adjacent ECM often moved forward, resulting in localized regions of ECM compression (Fig. 3F, arrows). Focal adhesion movements appeared to correlate with the ECM deformation observed by DIC in all cells studied. Cytochalasin D induced rapid disassembly of stress fibers and focal adhesions, cell elongation, and ECM relaxation (not shown).

\section{Cell Mechanical Behavior 2 to 7 Days after Plating}

Two to 7 days after plating within or on top of collagen matrices, human corneal fibroblasts continued to extend and retract pseudopodia, but generally did not undergo significant translocation. The mechanical activities of pseudopodia were similar at both ends of the cells, and it was difficult to distinguish "front" and "rear" in most cases. Spontaneous contrac- tion (Figs. 4A-C; see Video 2 in Appendix) of entire cells and the surrounding ECM was sometimes observed at these later time points, in contrast to the more localized contractile activity that was observed at the base of extending pseudopodia at 18 hours. Spontaneous contraction was observed in both transfected and control cells (in which only DIC imaging was performed), and thus was not induced by the fluorescent light used for GFP imaging. In one cell, spontaneous relaxation of the entire cell was observed (Figs. 4D-F, only one side of the cell is shown, to preserve resolution); this was immediately followed by cellular contraction (Fig. 4; see Video 3 in Appendix). Overall, human corneal fibroblasts appeared to switch from a migratory phenotype to a more stationary contractile phenotype between 18 hours and 2 days after plating in collagen matrices.

More prominent stress fibers (Figs. 4A, 4B, 4D, 4E, large arrows) were also observed in some cells 2 to 7 days after plating. When present, stress fibers were always aligned parallel with the direction of the cell-induced ECM displacements (Fig. 4B, 4E, red tracks), and they appeared to shorten and elongate during contraction and relaxation, respectively (Fig 4; see Videos 2, 3 in Appendix). The percentage of cells with detectable stress fibers did not increase significantly from 2 to 7 days. Focal adhesions were detected at the ends of the cells as well as along the cell body (Figs. $4 \mathrm{~A}, 4 \mathrm{~B}, 4 \mathrm{D}, 4 \mathrm{E}$, small arrows); those along the cell body were distinguished from stress-fiber-dense bodies by their larger size. An apparent correlation between ECM deformation and focal adhesion displacements was observed (Figs. 4C, 4F, compare red and white tracks). Despite the presence of stress fibers, we did not observe myofibroblast transformation under the conditions used in this study (as indicated by $\alpha$-smooth muscle actin staining [Petroll WM, Ma L, unpublished observation, 2003]).

\section{Effects of Serum Removal}

Switching the perfusion from $\mathrm{S}+$ to $\mathrm{S}-$ medium induced cell body elongation and a corresponding relaxation of tension on the matrix within 20 minutes at all time points studied (compare Figs. 5A-C; white arrows in $\mathrm{C}$ indicate direction of cell elongation). In most cases (seven of eight cells), rapid extension of pseudopodia was also observed, suggesting active cell spreading. Tractional forces continued to be generated by the extending pseudopodia as can best be appreciated in a timelapse movie in which the extension is shown within a superimposed circle (Fig. 5; see Video 4 in Appendix). Reperfusion with serum caused contraction of the cell, retraction of pseudopodia, and recompression of the matrix. Cytochalasin D always induced rapid disassembly of focal adhesions, cell elongation, and ECM relaxation without formation or extension of pseudopodia, confirming that pseudopodial extension in response to serum removal was an active process.

In one cell plated on top of the matrix, prominent stress fibers were observed (Figs. 5D-F). However, only a single 2-D plane was imaged in this early experiment, making it difficult to observe both stress fibers and focal adhesions simultaneously (because they were in different focal planes). Before switching the medium to $\mathrm{S}+$, we examined the focal adhesions (Fig. 5D). After cell and matrix relaxation induced by the switch to $\mathrm{S}-$ medium (Fig. 5E, large arrows and red tracks), both stress fibers (small arrow) and focal adhesions became visible in a single plane. Reperfusion with serum caused contraction of the cell, retraction of new filopodia, and compression of the matrix (Fig. 5F, large arrows and red tracks). Apparent shortening of the stress fibers after reperfusion is clearly seen in the time-lapse movie (Fig. 5; see Video 5 in Appendix). Note that the orientation of the stress fibers was parallel to the direction of matrix deformation (Fig. 5F, red 
FigURE 5. Effect of serum removal on cell contractility. (A-C) Cell 4, 7 days after plating within collagen matrix. The cell is shown after $204 \mathrm{~min}-$ utes of time-lapse imaging in S+ medium (A) and 20 (B) and 65 (C) minutes after the switch to $\mathrm{S}-$ medium. Switching from $S+$ to $S-$ medium induced cell body elongation (C, arrows) and release of tension on the matrix (red tracks). Active extension of pseudopodia was also observed (compare size of pseudopodia in $\mathbf{A}$ and $\mathbf{C}$ ). See Video 4 (refer to Appendix). (D-F). Cell 5, 3 days after plating on top of collagen matrix. (E) Cell is shown 95 minutes after switching to $S-$ medium. It began to relax after removal of serum (large arrows). Elongation correlated with release of tension on the ECM, as demonstrated by the matrix displacements (red tracks; + , positions just before the switch to S- medium). (F) Cell 26 minutes after reperfusion with $\mathrm{S}+$ medium. Switching back to $\mathrm{S}+$ medium caused contraction of the cell (large arrows), and compression of the matrix (red tracks; +, positions just before switching back to $\mathrm{S}+$ medium). A corresponding movement of focal adhesions was observed (compare white and red tracks in F). Stress fibers $(\mathbf{E}, \mathbf{F}$, small arrows) were also aligned with the measured ECM displacements. See Video 5 (refer to Appendix).

FigURE 6. Effect of the Rho-kinase inhibitor Y-27632 on cell contractility. (A-C) Cell 6, 1 day after plating within collagen matrix. The cell is shown after 129 minutes of timelapse imaging in $\mathrm{S}+$ medium (A) and 19 (B) and 34 (C) minutes after addition of Y-27632. Adding Y-27632 to $\mathrm{S}+$ medium induced cell elongation (B, C large arrows) and relaxation of tension on the matrix (red tracks). Rapid formation and extension of filopodia were also observed. Tips of extending filopodia were labeled with GFP- $\alpha$-actinin $(\mathbf{B}, \mathbf{C}$, small arrows). See Video 6 (refer to Appendix). (D-F) Cell 7, 2 days after plating within collagen matrix. (E) The cell 44 minutes after addition of Y-27632. Rapid relaxation of the cell (large arrows) and surrounding ECM was observed (red tracks; +, positions just before adding Y-27632). Filopodial formation and extension were also observed. Tips of extending filopodia were labeled with GFP$\alpha$-actinin (small arrows). See Video 7 (refer to Appendix). (F) Cell 69 minutes after reperfusion with $\mathrm{S}+$ medium. S+ medium induced contraction of the cell (large arrow), retraction of new filopodia, and recompression of the matrix (F, red tracks; + , positions just before reperfusion with $S+$ medium).
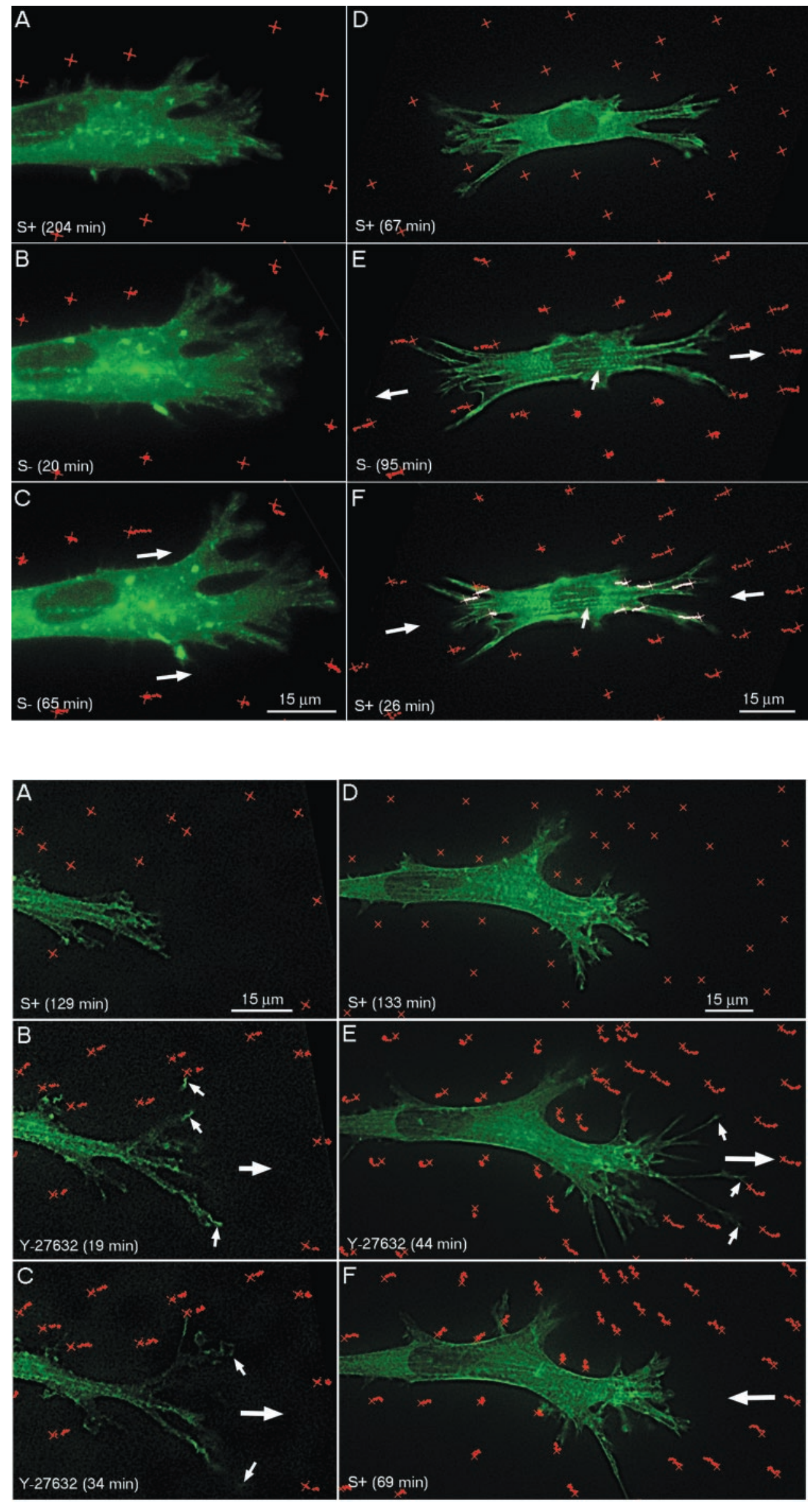

Downloaded from iovs.arvojournals.org on $09 / 15 / 2021$ 

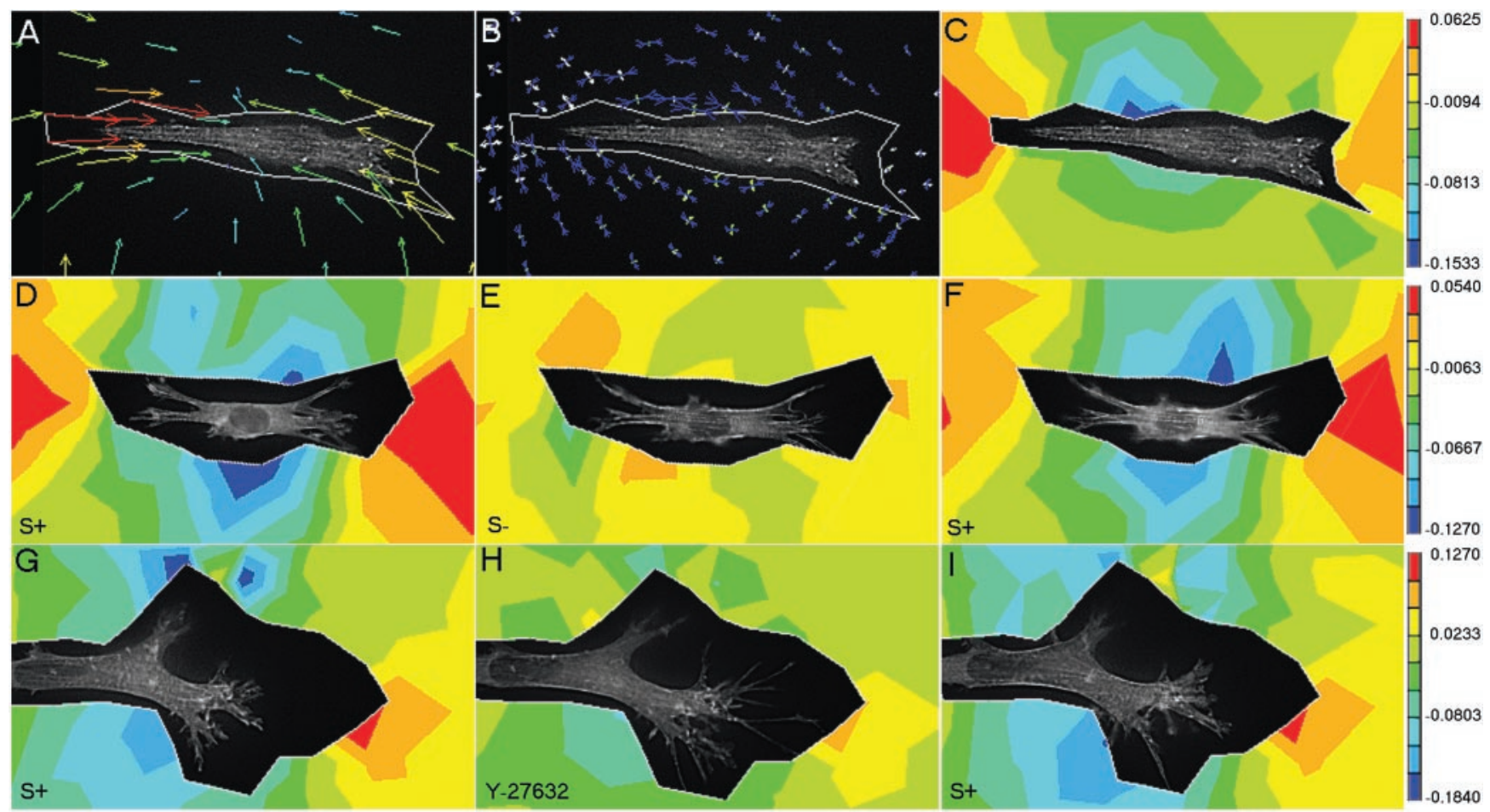

E

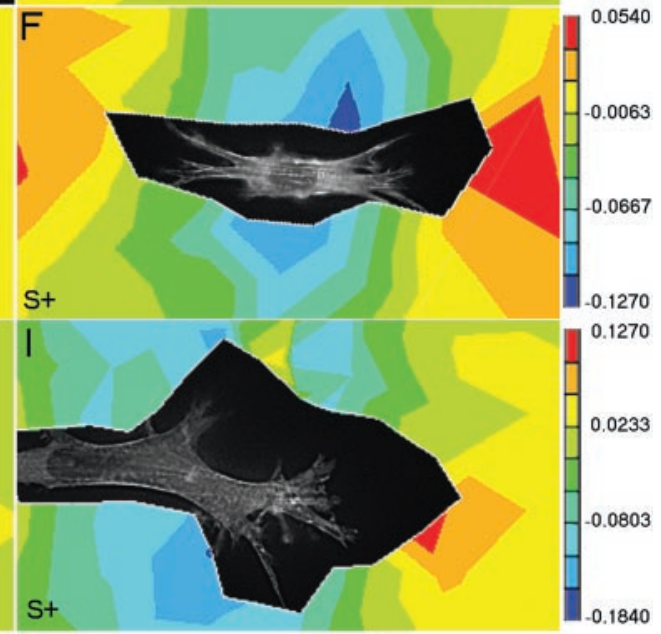

Figure 7. Analysis of matrix deformation using finite element modeling. (A-C) Cell 2. Tension generated by cell contraction as depicted by magnified displacement vectors (A), principal strains (B), and a contour map of strain along the $x$-axis (C). For principal strains (B), white indicates tension and blue indicates compression. Right: bar showing scale for color contour strain maps in dimensionless units $\Delta \mathrm{L} / \mathrm{L}$ (change in length/initial length). (D-F) Cell 5. Cell contraction in S + medium induced matrix tension at the ends (red) of the cell and compression (blue) in the middle (D). Switching to $\mathrm{S}-$ medium caused cell relaxation and a reduction of stress on the matrix (E). The process was reversed after the switch back to S+ (F). (G-I) Cell 7. Stress on the matrix in S+ medium (G) was reduced when Y-27632 was added to the medium (H). Stress was reestablished after the switch back to $\mathrm{S}+$ medium without Y-27632 (I). In all cases, strain is shown relative to the "relaxed" matrix configuration determined by treating cells with cytochalasin D and Triton X-100. See Video 8 (refer to Appendix)

tracks) during cell contraction. A correlation between deformation of the ECM and focal adhesion displacements (Fig. 5F, white tracks) was also observed.

\section{Effects of Inhibition of Rho-kinase}

Addition of the Rho-kinase inhibitor Y-27632 to S+ medium had a similar, but more rapid and dramatic effect than did the switch to S- medium (Fig. 6; see Videos 6, 7 in Appendix). Cell elongation and relaxation of tension were observed within 5 minutes (Figs. 6B, 6C, 6E, white arrows and red tracks). Rapid extension of existing pseudopodia and formation and extension of new filopodia were also observed, and extending filopodial tips were labeled with GFP- $\alpha$-actinin (Figs. 6B, 6C, $6 \mathrm{E}$, small arrows). After the initial cell relaxation, a slight, transient inward movement of collagen fibrils with respect to the surrounding ECM was observed in association with the tips of the cell processes, suggesting the generation of tractional force by extending pseudopodia. This traction was slight and difficult to detect without careful examination of the time-lapse movies (Fig. 6; Videos 6, 7, note action shown within the circles). When stress fibers were present, their clarity was reduced after incubation with Y-27632 (compare Figs. 6E with 6D, 6F). Switching back to $S+$ medium induced contraction of the cells, retraction of new filopodia, and recompression of the matrix (Fig. 6F, Video 6). Cytochalasin D induced rapid disassembly of stress fibers and focal adhesions, cell elongation, and ECM relaxation without formation and extension of filopodia (Video 6).

\section{Quantitative Analyses}

Finite element modeling was used to visualize better and to quantify the pattern of cell-induced matrix deformation during contraction and relaxation (Fig. 7). Finite element model strain maps show regions of cell-induced matrix tension and compression in response to the three conditions studied. Spontaneous contraction of cell 2 in $\mathrm{S}+$ medium induced matrix tension at the ends (Fig. $7 \mathrm{C}$, red and orange) of the cell and compression (blue and green) in the middle. Cell 5 induced a similar pattern of matrix deformation in S+ medium (Fig. 7D). However, switching to $S-$ caused a marked reduction of overall stress (both tension and compression) on the matrix (Fig. 7E). The process was reversed after the switch back to S+ medium (Fig. 7F). A similar relaxation of stress was induced in Cell 7 by inhibiting Rho-kinase (Figs. 7G, 7H; see Video 8 in Appendix); this process was also reversible (Fig. 7I).

To quantify the relationship between focal adhesion displacements and ECM deformation, the magnitude, and direction of the movement of adhesions and nearby ECM landmarks were compared. Three cells $(2,3$, and 5$)$ that had clearly visible stress fibers were used. Only focal adhesions that appeared to be at the ends of stress fibers were included in the analysis. Linear regression analysis demonstrated a statistically significant correlation between adhesion and ECM displacement ( $R=0.94, P<0.001$ ) with a slope of 0.71 (Fig. 8A). Thus in general, the magnitude of adhesion movement was larger than that of the ECM. The direction of adhesion and ECM movements also correlated highly ( $R=0.99, P<0.001$, Fig. 8B); however, the slope of this relationship was closer to 1 (slope $=$ 0.98).

We also measured the change in distance between consecutive GFP- $\alpha$-actinin-dense bodies along individual stress fibers before and after contraction in the same three cells. As shown in Figure 8C, there was variation in the measured change in 
FigURE 8. (A, B) Quantitative comparison of the magnitude and direction of the movement of adhesions and nearby ECM landmarks. Three cells $(2,3$, and 5$)$ that had clearly visible stress fibers were used. (A) Linear regression analysis demonstrated a statistically significant correlation between adhesion and ECM displacement with a slope of 0.71. (B) The direction of adhesion and ECM movements correlated highly; however, the slope of this relationship was closer to 1. (C, D) Quantitative analysis of stress fiber shortening. (C) The change in distance between consecutive GFP- $\alpha$-actinin-dense bodies along three individual stress fibers (SF) in cell 3 was measured during spontaneous contraction. Each symbol represents the measured change in distance between two consecutive dense bodies. (D) Stress fiber contraction (\% shortening) in three cells was quantified by measuring the average change in distance between dense bodies along three stress fibers. *Statistically significant shortening $(P<0.05)$.
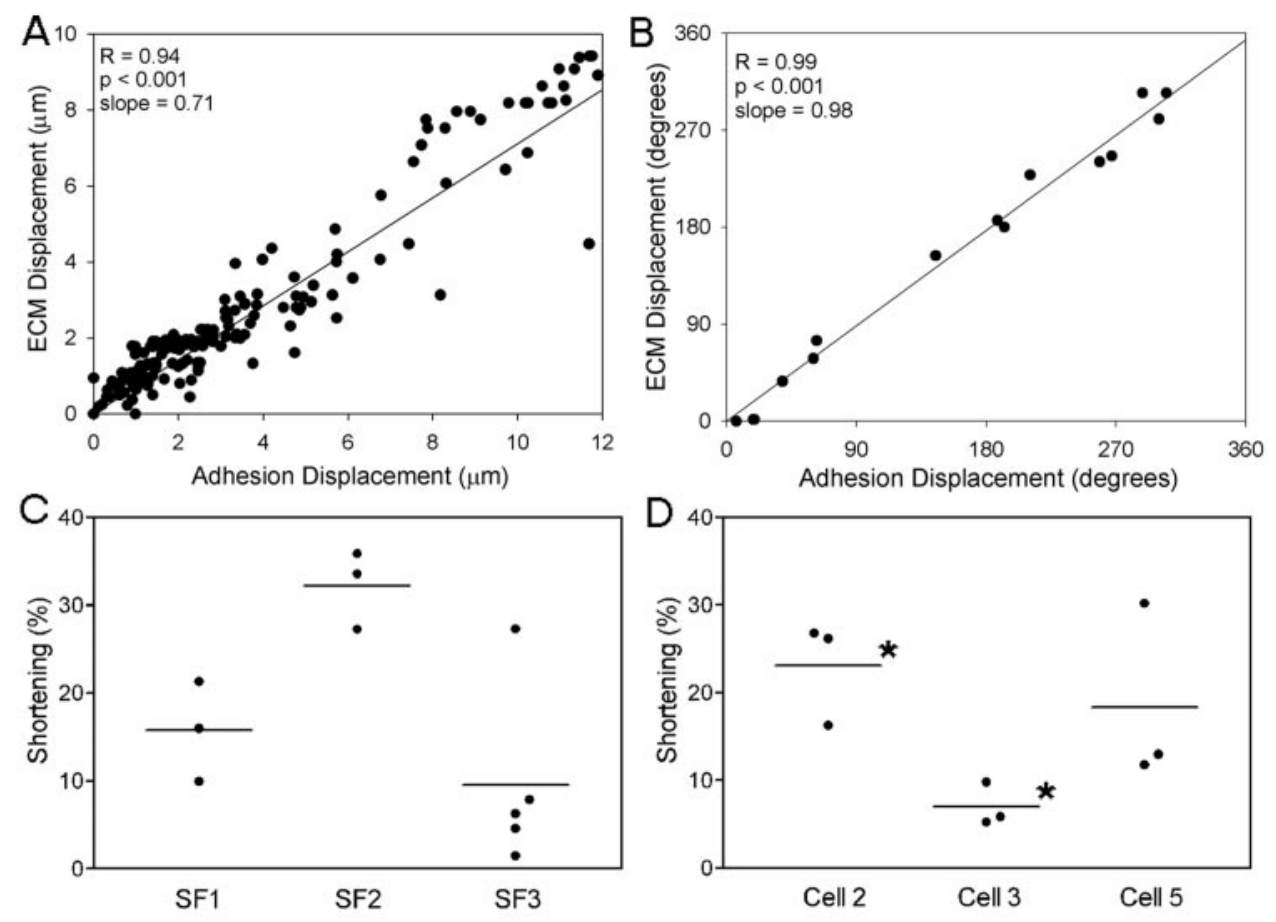

distance between consecutive dense bodies along each stress fiber. However, all stress fibers analyzed demonstrated some degree of shortening during cell contraction (Fig. 8D); and the amount of shortening was statistically significant in two cells (Fig. 8D, asterisks).

\section{Discussion}

Most previous work on cell motility and mechanical behavior has been performed using nonocular tissues, and very few studies have directly assessed the mechanical activity of isolated corneal fibroblasts. ${ }^{3,4,50,51,58,59}$ In this study, we used our recently generated extended-lifespan human corneal fibroblast cell line, HTK. ${ }^{46}$ This cell line was generated by transfection with the human telomerase reverse transcriptase gene (bTERT). ${ }^{60,61}$ Serum-cultured HTK cells have been shown to have a morphology and cytoskeletal organization similar to that of rabbit corneal fibroblasts, and TGF $\beta$ induces myofibroblast transformation of HTK cells, using a signal transduction pathway similar to that identified in both cultured human and rabbit keratocytes. ${ }^{46}$ Overall, the pattern of focal adhesion and matrix movement observed at 18 to 24 hours in human corneal fibroblasts expressing GFP- $\alpha$-actinin was similar to that previously observed in rabbit corneal fibroblasts expressing GFPzyxin. ${ }^{37,38}$ Focal adhesion formation and pseudopodial extension occurred at the front of the cells, whereas the rear was much less active and underwent intermittent retractions, resulting in cell translocation. During migration, tractional forces were generated by extending pseudopodial processes at the leading edge, while contractile forces pulled the cell body and adjacent ECM forward, resulting in localized regions of ECM compression at the base of cell processes.

Distinct changes in the cell's mechanical behavior were observed with extended time ( 2 to 7 days) in culture. First, spontaneous contraction of entire cells and the surrounding ECM was sometimes observed at these later time points, in contrast to the more localized contractile activity that was observed at the base of extending pseudopodia at 18 hours. Further investigation is needed to determine whether the spon- taneous changes we observed in contractility are due to potential environmental changes associated with our microincubation system (e.g., temperature fluctuations, perfusion with fresh media, $\mathrm{pH}$ change), or whether they are part of normal cell behavior. Second, cell migratory activity generally decreased over time. A similar decrease in cell migration is observed during in vivo wound healing as the wound space is repopulated, but this is presumably due to contact inhibition, which was not observed in our sparsely populated matrices.

Previous studies have demonstrated that the presence of stress fibers and strong focal adhesions tend to inhibit cell migration. ${ }^{44,62}$ In the present study, most cells did not form sufficiently large actin filament bundles to be detectable as stress fibers 18 hours after plating. However, extended time in culture led to the development of more prominent stress fibers in some cells. Apparently, additional local matrix remodeling by these cells from 18 to 48 hours provided the increased stiffness necessary for stress fiber formation. ${ }^{38,63}$ Cells with prominent stress fibers did not undergo significant translocation under any of the conditions used in this study, despite overall cell contraction and/or relaxation. Another factor that may influence cell migratory activity is a change in local matrix composition due to synthesis of ECM components (e.g., collagen, fibronectin) by the corneal fibroblasts. ${ }^{33}$ One limitation of our in vitro model is that the type I collagen matrices used do not contain other collagen types or proteoglycans that are normally present in the corneal stroma in vivo. ${ }^{64}$ Further investigation is needed to determine how ECM composition influences cell migratory activity.

During both dermal and corneal wound healing, adjacent corneal keratocytes transform to their active phenotype, migrate into the wound space, and exert forces to contract the tissue and reorganize the ECM. ${ }^{5,65-72}$ Fibroblasts within the wound develop a musclelike myofibroblast phenotype characterized by prominent actin stress fiber bundles rich in $\alpha$-smooth muscle actin. ${ }^{68,69,73}$ Myofibroblasts appear to form a putative contractile apparatus, comprised of intracellular Factin microfilament bundles, $\alpha$-actinin, and nonmuscle myosin, which is linked to the ECM by focal contacts. ${ }^{74,75}$ The devel- 


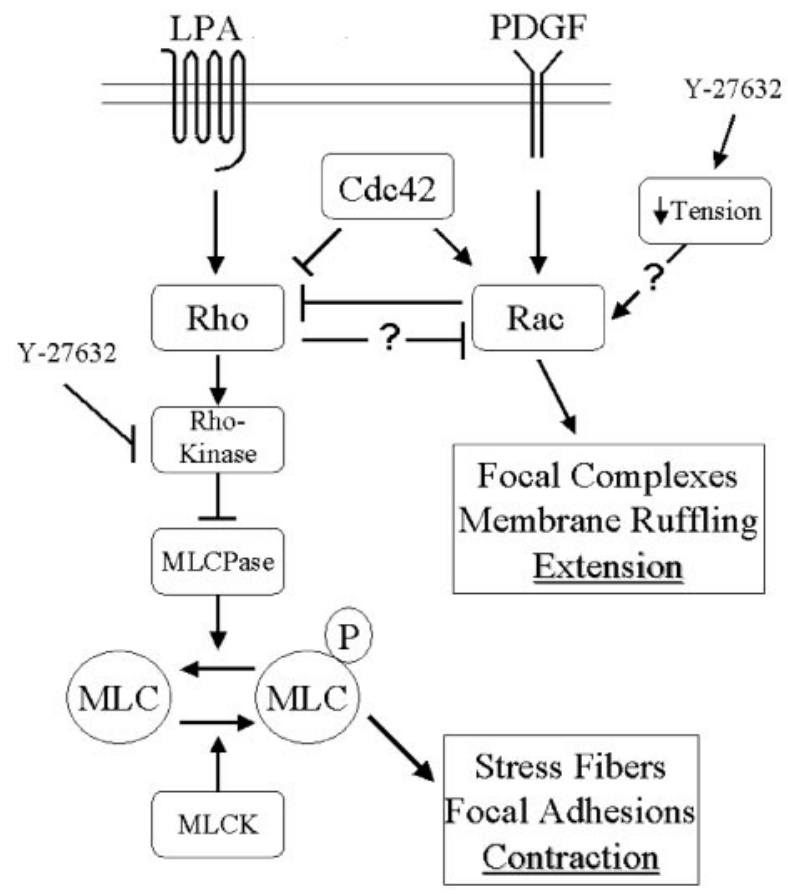

FIGURE 9. A simplified diagram of the Rho and Rac signaling pathways.

opment of a contractile apparatus within wound-healing fibroblasts suggests that sarcomeric-like shortening of the actomyosin filaments may generate the forces to pull the wound edges together. ${ }^{68,76,77}$ Contraction of stress fiber sarcomeres has been demonstrated in response to magnesium-adenosine triphosphate (MgATP) in detergent-extracted cells microinjected with rhodamine-labeled $\alpha$-actinin, by measuring the shortening between $\alpha$-actinin-dense bodies along the stress fibers. ${ }^{78}$ However, sarcomeric shortening of stress fibers has not been directly measured in intact living cells.

In this study, we measured the distance between GFP- $\alpha$ actinin-dense bodies along stress fibers in three cells. Shortening ranged from $5 \%$ to $30 \%$, consistent with the sarcomeric shortening of $25 \%$ previously measured in detergent-extracted cells. $^{78}$ Stress fibers that have been completely isolated from cells have been shown to shorten an average of $77 \%$ in the presence of MgATP, and this contraction is dependent on myosin light-chain kinase (MLCK) activity. ${ }^{56}$ In a cellular-contraction-based model of wound healing, the force generated by actomyosin filaments would be directed along the axis of the stress fiber bundles. When present, stress fibers were always oriented parallel to the direction of tension generation on the ECM in the present study. Furthermore, the magnitude and direction of movement of focal adhesions at the ends of stress fibers correlated significantly with the ECM displacement. In general, the adhesion displacements were larger than those of the ECM. This is consistent with our previous observation that collagen fibrils with which the cell directly interacts often undergo larger movements than the surrounding mesh of interconnected collagen fibrils. ${ }^{38}$ Although we cannot rule out the contribution of other contractile components of the cell (e.g., the cell cortex). Overall, the data suggest that, when present, stress fibers may play an important role in cellular force generation.

Several studies have suggested that cell contractility requires stimulation by serum or other growth factors. ${ }^{39-42}$ In this study, we observed rapid and reversible cell body elongation and relaxation of tension on the matrix after switching from $S+$ to $S-$ medium in all cells studied. Active cell spreading was unexpectedly induced in most cases, and tractional forces continued to be generated by extending pseudopodia. These results suggest that contractile force generation along the cell body and tractional force generation at the leading edge may be differentially regulated. To investigate this possibility further, we also studied the effects of Rho-kinase inhibition on corneal fibroblast mechanical activity.

Studies have established that the Rho-family GTPases Rho and Rac regulate cell contraction and spreading, respectively. ${ }^{43}$ In Swiss 3T3 fibroblasts, Rho stimulates the formation of stress fibers and large focal adhesions, whereas Rac and Cdc42 induce the creation of smaller focal complexes, lamellipodial ruffling and filopodial extension (Fig. 9). ${ }^{45,79-81}$ Rac activity is generally upregulated by platelet-derived growth factor (PDGF). ${ }^{18,79}$ Both Rho and Rac appear to stimulate myosin II contractility, because inhibition of MLCK blocks formation of both Rho-induced focal adhesions and Rac-induced focal complexes. ${ }^{81}$ Rho promotes increased phosphorylation of myosin light chain through Rho-kinase inhibition of myosin light chain phosphatase (MLCPase). ${ }^{45,82,83}$ Lysophosphatidic acid (LPA) has been shown to be the serum component primarily responsible for stimulating cell contractility, ${ }^{39,84-87}$ and LPA is known to act through the small GTPase Rho. ${ }^{45,82,83}$ However, serum contains numerous other growth factors, including PDGF. Thus, both Rho and Rac are presumably upregulated in corneal fibroblasts cultured in serum.

Despite progress in our understanding of Rho and Rac regulation of cell mechanical activity, many details of their individual signal transduction pathways and the interaction between them are unknown. Furthermore, the effects of Rho and Rac can vary substantially, depending on cell type, and their role in regulating corneal fibroblast contractility has not been directly assessed. Our data demonstrate that inhibition of Rho-kinase results in decreased contractility in human corneal fibroblasts, presumably by reducing Rho-kinase inhibition of MLCPase. Several studies suggest that there is cross-talk between the Rho and Rac signaling pathways, and that mutually antagonist pathways exist between them. ${ }^{79,81}$

A recent study by Katsumi et al. ${ }^{88}$ suggests that Rac activity in vascular smooth muscle cells may also be tension-dependent. Mechanical stretching of cells was shown to downregulate Rac, whereas decreasing mechanical tension (by inhibiting Rho-kinase) upregulated Rac. Consistent with these data, we observed rapid pseudopodial and/or filopodial extension coincident with cell relaxation after Rho-kinase inhibition, suggesting a relative increase in Rac activity. Others have demonstrated that Rho or Rho-kinase inhibition decreases the overall contraction of collagen matrices, ${ }^{45,63,89}$ reduces force generation by a mass culture of cells, ${ }^{90}$ and blocks LPA-induced retraction of dendritic cell processes in floating collagen matrices. ${ }^{91}$ However, to our knowledge, this is the first study to demonstrate directly the effect of Rho-kinase inhibition on the subcellular pattern of force generation by individual cells in a 3-D model.

Recently, Galbraith et al. ${ }^{92}$ investigated the relationship between force and focal complex development during spreading of NIH 3T3 fibroblasts by using beads coated with a fragment of fibronectin type III which elicits Rac-dependent focal complex assembly. The development of focal complexes (and force) was inhibited by dominant-negative Rac and by inhibition of MLCK, but not by dominant-negative Rho, suggesting that tractional force generation during Rac-induced cell spreading can occur without Rho-kinase activity. We also found that tractional forces were generated by extending pseudopodia after the initial cell body relaxation induced by inhibition of Rho-kinase, as indicated by small transient displacements of collagen fibrils, suggesting that the subcellular pattern of force 
generation inside 3-D matrices may also be differentially regulated by Rho and Rac. Previous studies have shown that inhibition of Rho-kinase causes a significant increase in the rate of migration by rat embryo fibroblasts after scrape injury to a confluent monolayer. ${ }^{44}$ We did not observe an increase in directional migration in response to Rho-kinase inhibition in this study. Instead, cell spreading was observed at both ends of these bipolar cells. This difference in behavior probably exists because cells in a confluent monolayer can spread only into the denuded wound space, since they are in contact with other cells behind and alongside them. It should be noted that Y-27632 has been shown to inhibit cell migration by smooth muscle cells and intestinal epithelium. ${ }^{93,94}$

Although we did not observe myofibroblast transformation at the low density used in this study; studies using dermal fibroblasts have shown that collagen lattice contraction by both fibroblasts and myofibroblasts is dependent on MLCK ${ }^{8,92}$ and is stimulated by activation of Rho. ${ }^{18,45}$ Thus, common pathways may regulate contractile force generation in both myofibroblasts and fibroblasts. Future studies performed under different culture conditions (e.g., PDGF, TGF $\beta$ ) using this experimental technique should continue to provide insights into the underlying mechanisms regulating cell motility, contraction, and matrix remodeling.

\section{References}

1. Stopak D, Harris AK. Connective tissue morphogenesis by fibroblast traction. Dev Biol. 1982;90:383-398.

2. Stopak D, Wessels NK, Harris AK. Morphogenetic rearrangement of injected collagen in developing chicken limb buds. Proc Natl Acad Sci USA. 1985;82:2804-2808.

3. Bard JBL, Hay ED. The behavior of fibroblasts from the developing avian cornea: morphology and movement in situ and in vitro.J Cell Biol. 1975;67:400 - 418 .

4. Bard JBL, Higginson K. Fibroblast-collagen interactions in the formation of the secondary stroma of the chick cornea. J Cell Biol. 1977;74:816-827.

5. Gabbiani G, Hirschel BJ, Ryan GB, Statkov PR, Majno G. Granulation tissue as a contractile organ: a study of structure and function. J Exp Med. 1972;135:719-734.

6. Ehrlich HP. Wound closure: evidence of cooperation between fibroblasts and collagen matrix. Eye. 1988;2:149-157.

7. Martin P. Wound healing: aiming for perfect skin regeneration. Science. 1997;276:75-81.

8. Hardin-Young J, Parenteau NL. Bilayered skin constructs. In: Atala A, Lanza RP, eds. Methods of Tissue Engineering. San Diego: Academic Press; 2002;1177-1188.

9. Bell E, Ivarsson B, Merril C. Production of a tissue-like structure by contraction of collagen lattices by human fibroblasts of different proliferative potential in vivo. Proc Natl Acad Sci USA. 1979;76: $1274-1278$

10. Elsdale T, Bard J. Collagen substrata for studies on cell behavior. J Cell Biol. 1972;54:626-637.

11. Grinnell F, Lamke CR. Reorganization of hydrated collagen lattices by human skin fibroblasts. J Cell Sci. 1984;66:51-63.

12. Cheema U, Yang S-Y, Mudera V, Goldspink GG, Brown RA. 3-D in vitro model of early skeletal muscle development. Cell Motil Cytoskeleton. 2003;54:226-236.

13. Eastwood M, McGrouther DA, Brown RA. A culture force monitor for measurement of contraction forces generated in human dermal fibroblast cultures: Evidence for cell matrix mechanical signalling. Biochim Biophys Acta. 1994;1201:186-192.

14. Kolodney MS, Wysolmerski RB. Isometric contraction by fibroblasts and endothelial cells in tissue culture: a quantitative study. J Cell Biol. 1992;117:73-82.

15. Arora PD, Narani N, McCulloch CAG. The compliance of collagen gels regulates transforming growth factor-beta induction of alphasmooth muscle actin in fibroblasts. Am J Pathol. 1999;154:871882.
16. Brown RA, Prajapati R, McGrouther DA, Yannas IV, Eastwood M. Tensional homeostasis in dermal fibroblasts: mechanical responses to mechanical loading in three-dimensional substrates. $J$ Cell Physiol. 1998;175:323-332.

17. Freyman TM, Yannas IV, Yokoo R, Gibson LJ. Fibroblast contractile force is independent of the stiffness which resists the contraction. Exp Cell Res. 2002;272:153-162.

18. Grinnell F. Fibroblast-collagen matrix contraction: growth-factor signalling and mechanical loading. Trends Cell Biol. 2000;10:362365.

19. Rosenfeldt H, Lee DJ, Grinnell F. Increased c-fos mRNA expression by human fibroblasts contracting stressed collagen matrices. $\mathrm{Mol}$ Cell Biol. 1998;18:2659-2667.

20. Shreiber DI, Enever PAJ, Tranquillo RT. Effects of PDGF-BB on rat dermal fibroblast behavior in mechanically stressed and unstressed collagen and fibrin gels. Exp Cell Res. 2001;266:155-166.

21. Skuta G, Ho C-H, Grinnell F. Increased myosin light chain phosphorylation is not required for growth factor stimulation of collagen matrix contraction. J Biol Chem. 1999;274:30163-30168.

22. Vaughan MB, Howard EW, Tomasek JJ. Transforming growth factor-b1 promotes the morphological and functional differentiation of the myofibroblast. Exp Cell Res. 2000;257:180-189.

23. Harris AK, Wild P, Stopak D. Silicone rubber substrata: a new wrinkle in the study of cell locomotion. Science. 1980;208:177189.

24. Harris AK, Stopak D, Wild P. Fibroblast traction as a mechanism for collagen morphogenesis. Nature. 1981;290:249-251.

25. Lee J, Leonard M, Oliver T, Ishihara A, Jacobson $\mathrm{K}$. Traction forces generated by locomoting keratocytes. J Cell Biol. 1994;127:19571964.

26. Oliver T, Dembo M, Jacobson K. Traction forces in locomoting cells. Cell Motil Cytoskeleton. 1995;31:225-240.

27. Balaban NQ, Schwarz US, Riveline D, et al. Force and focal adhesion assembly: a close relationship studied using elastic micropatterned substrates. Nat Cell Biol. 2001;3:466-3472.

28. Pelham RJ Jr, Wang Y. Cell locomotion and focal adhesions are regulated by substrate flexibility. Proc Natl Acad Sci USA. 1997; 94:13661-13665.

29. Wang YL, Pelham RJ Jr. Preparation of a flexible, porous polyacrylamide substrate for mechanical studies of cultured cells. Methods Enzymol. 1998;298:489-496.

30. Pelham RJ, Wang Y. High resolution detection of mechanical forces exerted by locomoting fibroblasts on the substrate. Mol Biol Cell. 1999;10:935-945.

31. Beningo KA, Dembo M, Kaverina I, Small JV, Wang YL. Nascent focal adhesions are responsible for the generation of strong propulsive forces in migrating fibroblasts. J Cell Biol. 2001;153:881888.

32. Cukierman E, Pankov R, Stevens DR, Yamada KM. Taking cellmatrix adhesions to the third dimension. Science. 2001;294:17081712 .

33. Cukierman E, Pankov R, Yamada KM. Cell interactions with threedimensional matrices. Curr Opin Cell Biol. 2002;14:633-639.

34. Doane KJ, Birk DE. Fibroblasts retain their tissue phenotype when grown in three-dimensional collagen gels. Exp Cell Res. 1991;195: 432-442.

35. Friedl P, Brocker E-B. The biology of cell locomotion within threedimensional extracellular matrix. Cell Mol Life Sci. 2000;57:41-64.

36. Tomasek JJ, Hay ED, Fujiwara K. Collagen modulates cell shape and cytoskeleton of embryonic corneal and fibroma fibroblasts: distribution of actin, $\alpha$-actinin and myosin. Dev Biol. 1982;92:107122.

37. Petroll WM, Ma L, Jester JV. Direct correlation of collagen matrix deformation with focal adhesion dynamics in living corneal fibroblasts. J Cell Sci. 2003;116:1481-1491.

38. Petroll WM, Ma L. Direct, dynamic correlation of cell-matrix interactions inside fibrillar collagen matrices. Cell Motil Cytoskeleton. 2003;55:254-264.

39. Ridley AJ, Hall A. The small GTP-binding protein rho regulates the assembly of focal adhesions and actin stress fibers in response to growth factors. Cell. 1992;80:389-399. 
40. Chrzanowska-Wodnicka C, Burridge K. Rho-stimulated contractility drives the formation of stress-fibers and focal adhesions. J Cell Biol. 1996;133:1403-1415.

41. Tomasek JJ, Haaksma CJ, Eddy RJ, Vaughan MB. Fibroblast contraction occurs on release of tension in attached collagen lattices: dependency on an organized actin cytoskeleton and serum. Anat Rec. 1992;232:359-368.

42. Roy P, Petroll WM, Cavanagh HD, Jester JV. Exertion of tractional force requires the coordinated upregulation of cell contractility and adhesion. Cell Motil Cytoskeleton. 1999;43:23-34.

43. Kaverina I, Krylyshkina O, Small JV. Regulation of substrate adhesion dynamics during cell motility. Int J Biochem Cell Biol. 2002; 34:746-761.

44. Nobes CD, Hall A. Rho GTPases control polarity, protrusion, and adhesion during cell movement. J Cell Biol. 1999;144:1235-1244.

45. Parizi M, Howard EW, Tomasek JJ. Regulation of LPA-promoted myofibroblast contraction: role of rho, myosin light chain kinase, and myosin light chain phosphatase. Exp Cell Res. 2000;254:210 220.

46. Jester JV, Huang J, Fisher S, et al. Myofibroblast differentiation of normal human keratocytes and hTERT, extended-life, human corneal fibroblasts. Invest Ophthalmol Vis Sci. 2003;44:1850-1858.

47. Edlund E, Lotano MA, Otey CA. Dynamics of $\alpha$-actinin in focal adhesions and stress fibers visualized with $\alpha$-actinin green fluorescent protein. Cell Motil Cytoskeleton. 2001;48:190-200.

48. Rajfur Z, Roy P, Otey C, Romer L, Jacobsen K. Dissecting the link between stress fibres and focal adhesions by CALI with EGFP fusion proteins. Nat Cell Biol. 2002;4:286-293

49. Vanni S, Lagerholm BC, Otey C, Taylor DL, Lanni F. Internet-based image analysis quantifies contractile behavior of individual fibroblasts inside model tissue. Biophys J. 2003;84:2715-2727.

50. Roy P, Petroll WM, Chuong CJ, Jester JV. Effect of cell migration on the maintenance of tension on collagen matrix. Ann Biomed Eng. 1999;27:721-730.

51. Roy P, Petroll WM, Cavanagh HD, Chuong CJ, Jester JV. An in vitro force measurement assay to study the early mechanical interaction between corneal fibroblasts and collagen matrix. Exp Cell Res. 1997;232:106-117.

52. Dembo M, Wang YL. Stresses at the cell-to-substrate interface during locomotion of fibroblasts. Biophys J. 1999;76:2307-2316.

53. Timoshenko S. Axially symmetrical stress distribution in a solid of revolution. In: Theory of Elasticity. New York: McGraw-Hill: London; 1934;309-380.

54. Roeder BA, Kokini K, Sturgis JE, Robinson JP, Voytik-Harbin SL. Tensile mechanical properties of three-dimensional type I collagen extracellular matrices with varied microstructure. Trans ASME. 2002;124:214-222.

55. Lazarides E, Burridge K. $\alpha$-actinin: immunofluorescent localization of a muscle structural protein in nonmuscle cells. Cell. 1975;6: $289-298$

56. Katoh K, Kano Y, Masuda M, Onishi H, Fujiwara K. Isolation and contraction of the stress fiber. Mol Biol Cell. 1998;9:1919-1938.

57. Jester JV, Barry PA, Lind GJ, Petroll WM, Garana R, Cavanagh HD. Corneal keratocytes: in situ and in vitro organization of cytoskeletal contractile proteins. Invest Ophthalmol Vis Sci. 1994;35:730 743.

58. Hay ED. Interaction of migrating embryonic cells with extracellular matrix. Exp Biol Med. 1985;10:174-193.

59. Tomasek JJ, Hay ED. Analysis of the role of microfilaments and microtubules in acquisition of bipolarity and elongation of fibroblasts in hydrated collagen gels. J Cell Biol. 1984;99:536-549.

60. Steinert S, White DM, Zou Y, Shay JW, Wright WE. Telomere biology and cellular aging in nonhuman primate cells. Exp Cell Res. 2002;272:146-152.

61. Bodnar AG, Ouellette M, Frolkis M, et al. Extension of life-span by introduction of telomerase into normal human cells. Science. 1998;279:349-352.

62. Friedl P, Zanker K, Brocker E-B. Cell migration strategies in 3-D extracellular matrix: differences in morphology, cell matrix interactions, and integrin function. Microsc Res Tech. 1998;43:369378.
63. Tamariz E, Grinnel F. Modulation of fibroblast morphology and adhesion during collagen matrix remodeling. Mol Biol Cell. 2002; 13:3915-3929.

64. Nishida T. Cornea. In: Krachmer JH, Mannis MJ, Holland EJ, eds. Cornea: Fundamentals of Cornea and External Disease. St. Louis; Mosby-Year Book, Inc.; 1997:3-28.

65. Gabbiani G, Ryan GB, Majno G. Presence of modified fibroblasts in granulation tissue and their possible role in wound contraction. Experientia. 1971;27:549-550.

66. Gabbiani G, Chaponnier C, Huttner I. Cytoplasmic filaments and gap junctions in epithelial cells and myofibroblasts during wound healing. J Cell Biol. 1978;76:561-568.

67. Gabbiani G. The biology of the myofibroblast. Kidney Int. 1992; 41:530-532.

68. Darby I, Skalli O, Gabbiani G. $\alpha$-smooth muscle actin is transiently expressed by myofibroblasts during experimental wound healing. Lab Invest. 1990;63:21-29.

69. Skalli O, Gabbiani G. The biology of the myofibroblast relationship to wound contraction and fibrocontractive disease. In: Clark RAF, Henson PM, eds. The Molecular and Cellular Biology of Wound Repair. New York: Plenum Press; 1988;373- 402.

70. Lutrull J, Smith R, Jester JV. In vitro contractility of avascular corneal wounds in rabbit eyes. Invest Ophthalmol Vis Sci. 1985; 26:1449-1452.

71. Jester JV, Rodrigues MM, Herman IM. Characterization of avascular corneal wound healing fibroblasts: new insights into the myofibroblasts. Am J Pathol. 1987;127:140 -148.

72. Jester JV, Petroll WM, Feng W, Essepian J, Cavanagh HD. Radial keratotomy: I. The wound healing process and measurement of incisional wound gape in two animal models using in vivo, confocal microscopy. Invest Ophthalmol Vis Sci. 1992;33:3255-3270.

73. Jester JV, Petroll WM, Barry PA, Cavanagh HD. Expression of $\alpha$-smooth muscle ( $\alpha$-SM) actin during corneal stromal wound healing. Invest Ophthalmol Vis Sci. 1995;36:809-819.

74. Garana RMR, Petroll WM, Herman I, et al. Radial keratotomy: II. Role of the myofibroblast in corneal wound contraction. Invest Ophthalmol Vis Sci. 1992;33:3271-3282.

75. Welch M, Odland G, Clark R. Temporal relationships of f-actin bundles formation, collagen and fibronectin matrix assembly, and fibronectin receptor expression to wound contraction. J Cell Biol. 1990;110:133-145.

76. Byers HR, White GE, Fujiwara K. Organization and function of stress fibers in cells in vitro and in situ: a review. Cell Muscle Motil. 1984;5:83-137.

77. Majno G, Gabbiani G, Hirschel BJ, Ryan GB, Statkov PR. Contraction of granulation tissue in vitro: similarity to smooth muscle. Science. 1971;173:548-550.

78. Kreis TE, Birchmeier W. Stress fiber sarcomeres of fibroblasts are contractile. Cell. 1980;22:555-561.

79. Sander EE, ten Klooster JP, van Delft S, van der Kammen RA, Collard JG. Rac downregulates Rho activity: reciprocal balance between both GTPases determines cellular morphology and migratory behavior. J Cell Biol. 1999;147:1009-1021.

80. Totsukawa G, Yamakita Y, Yamashiro S, Hartshorne DJ, Sasaki Y. Distinct roles of ROCK (Rho-kinase) and MLCK in spatial regulation of MLC phosphorylation for assembly of stress fibers and focal adhesions in 3T3 fibroblasts. J Cell Biol. 2000;150:797-806.

81. Rottner K, Hall A, Small JV. Interplay between Rac and Rho in the control of substrate contact dynamics. Curr Biol. 1999;9:640648.

82. Kimura K, Ito M, Amano M, et al. Regulation of myosin phosphatase by rho and rho-associated kinase (Rho-kinase). Science. 1996; 273:245-248.

83. Chrzanowska-Wodnicka C, Burridge K. Tyrosine phosphorylation is involved in reorganization of the actin cytoskeleton in response to serum or LPA stimulation. J Cell Sci. 1994;107:3643-3654.

84. Kolodney MS, Elson EL. Correlation of myosin light chain phosphorylation with isometric contraction of fibroblasts. J Biol Chem. 1993;268:23850-23855.

85. Tomasek JJ, McConathy WJ, Checovich WJ, Mosher DF. Lipoproteins promote fibroblast-mediated collagen lattice contraction (Abstract). Mol Biol Cell. 1992;3:234A. 
86. Sanderson PL, Morris AM, Stanley JK, Fahmy NRM. Lipids and Dupuytren's disease. J Bone Joint Surg. 1992;74:723-927.

87. Rayan GM, Parizi M, Tomasek JJ. Pharmacologic regulation of Dupuytren's fibroblast contraction in vitro. J Hand Surg. 1996;21: 1065-1070.

88. Katsumi A, Milanini J, Kiosses WB, et al. Effects of cell tension on the small GTPase Rac. J Cell Biol. 2002;158:153-164.

89. Han Y-P, Nien Y-D, Garner WL. Recombinant human platelet derived growth factor and transforming growth factor $\beta$ mediated contraction of human dermal fibroblast populated lattices is inhibited by Rho/GTPase inhibitor but does not require phosphatidylinositol-3' kinase. Wound Rep Reg. 2002;10:169-176.

90. Nobe H, Nobe K, Fazal F, De Lanerolle P, Paul RJ. Rho kinase mediates serum-induced contraction in fibroblast fibers independent of myosin $\mathrm{LC}_{20}$ phosphorylation. Am J Physiol. 2003;284: C599-C606.

91. Grinnell F, Ho C-H, Tamariz E, Lee DJ, Skuta G. Dendritic fibroblasts in three-dimensional collagen matrices. Mol Biol Cell. 2003; 14:384-395.

92. Galbraith CG, Yamada KM, Sheetz MP. The relationship between force and focal complex development. J Cell Biol. 2002;159:695705.

93. Ai S, Kuzuya M, Koike T, et al. Rho-Rho kinase is involved in smooth muscle cell migration through myosin light chain phosphorylation-dependent and independent mechanisms. Atherosclerosis. 2001;155:321-327.

94. Rao JN, Gua X, Liu L, et al. Polyamines regulate Rho-kinase and myosin phosphorylation during intestinal epithelial restitution. Am J Physiol. 2003;284:C848-C859.

\section{APPENDIX: Video Descriptions}

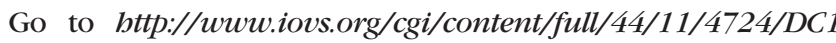
to view the following videos.

Video 1. Color overlay of GFP- $\alpha$-actinin 3-D reconstruction (green) and 2-D DIC image (red) 18 hours after plating the cell within collagen matrix. Interactions between focal adhesions and collagen fibrils can be directly visualized.

Video 2. Spontaneous contraction of corneal fibroblasts in $\mathrm{S}+$ medium, 3 days after plating within collagen matrix. During perfusion with $\mathrm{S}+$ medium, the entire cell began to contract and generate tension on the ECM. Stress fibers were aligned with the ECM displacements and appeared to shorten during contraction.

Video 3. Corneal fibroblasts plated on top of collagen matrix and cultured in $\mathrm{S}+$ medium for 2 days. Spontaneous relaxation of the entire cell was observed, followed immediately followed by cellular contraction. Red tracks show measured ECM displacements.
Video 4. A corneal fibroblast 7 days after plating within collagen matrix. The sequence begins immediately after the medium was switched from $\mathrm{S}+$ to $\mathrm{S}-$. Cell body elongation, matrix relaxation, and active extension of pseudopodia were observed. Note the relative inward movement of ECM in front of the cell (encircled) in comparison with the overall ECM relaxation, suggesting tractional force generation by extending pseudopodia.

Video 5. A corneal fibroblast 3 days after plating within collagen matrix. The sequence begins immediately after the medium was switched from $\mathrm{S}-$ to $\mathrm{S}+$. Cell body contraction, matrix compression, and apparent stress fiber shortening were observed.

Video 6. A corneal fibroblast 1 day after plating within collagen matrix. The sequence begins immediately after Y-27632 was added to S+ medium. Addition of Y-27632 induced rapid relaxation of the cell and surrounding ECM. Filopodial formation and extension were observed. Tips of extending filopodia were labeled with GFP- $\alpha$-actinin. Note the transient relative inward movement of ECM in front of the cell (encircled) in comparison with the overall ECM relaxation, suggesting tractional force generation by extending pseudopodia. Reperfusion with $\mathrm{S}+$ medium induced contraction of the cell, retraction of new filopodia, and recompression of the matrix. Cytochalasin D induced rapid disassembly of stress fibers and focal adhesions, cell elongation, and ECM relaxation without formation and extension of filopodia.

Video 7. A corneal fibroblast 2 days after plating within collagen matrix. Adding Y-27632 to S+ medium induced cell elongation and relaxation of tension on the matrix. Rapid formation and extension of filopodia were also observed. Tips of extending filopodia were labeled with GFP- $\alpha$-actinin. Note the transient relative inward movement of ECM in front of the cell (circle) in comparison with the overall ECM relaxation, suggesting tractional force generation by extending pseudopodia.

Video 8. GFP- $\alpha$-actinin transfected corneal fibroblast (white) two days after plating within collagen matrix surrounded by finite element model strain maps generated using engineering analysis software (ANSYS, ver. 7.0; ANSYS, Inc.), showing regions of matrix tension (red and orange) and compression (blue). Bar on right of Figure 7I shows scale for color contour strain maps. Stress on the matrix in S+ medium was reduced when the cell was switched to Y-27632-supplemented medium. Stress was reestablished after the switch back to $\mathrm{S}+$ medium. Note that the clarity of the stress fibers was reduced after incubation with Y-27632. 